\title{
A competência para Educação Permanente em Saúde: percepções de coordenadores de graduações da saúde
}

| ${ }^{1}$ Luciana Portes de Souza Lima, ${ }^{2}$ Mara Regina Rosa Ribeiro |

Resumo: Estudo descritivo, exploratório, de abordagem qualitativa. Teve como objetivo compreender a percepção dos coordenadores de cursos da saúde - Nutrição, Enfermagem, Medicina e Psicologia - sobre Educação Permanente em Saúde (EPS) e identificar quais habilidades, conhecimentos e atitudes compõem essa competência. Abordamos nossos resultados em dois momentos, a saber: 1) Concepçōes acerca da EPS, e 2) A composição da competência para EPS. Entendemos que os desafios para a incorporação dos princípios da EPS são os mesmos encontrados para a ruptura dos processos tradicionais de ensino-aprendizagem.

> Palavras-chave: educação; educação continuada; educação permanente em saúde.
1 Universidade Federal do Mato Grosso. Cuiabá-MT, Brasil (lu_souz@hotmail.com).

2 Faculdade de Enfermagem, Universidade Federal do Mato Grosso. Cuiabá-MT, Brasil (mrrribeiro10@gmail.com). 


\section{Introdução}

Compreendendo que a educação não se restringe apenas a uma etapa da vida, e sim permeia toda a existência do ser humano, assumimos que o cotidiano do trabalho pode constituir-se como um "ambiente pedagógico", assim como a universidade (CECCIM, 2005). Os cursos de graduação, independente da área, estão contidos em um espaço de tempo determinado, com duração de alguns anos; porém, os processos rotineiros de trabalho permanecem por várias décadas, tornando-se o ambiente ideal para instituirmos processos contínuos de ensino-aprendizagem, diretamente articulados com a prática. Assim, seria papel da universidade desenvolver no graduando competências para aprender permanentemente, descentralizando a instituição de ensino e o professor e centralizando o próprio estudante e futuro trabalhador no processo de aprender.

Ao utilizarmos a palavra competência, concordamos com Perrenoud (1999) que esta não se limitaria apenas à aquisição de conhecimentos, mas seria um conjunto de esquemas que, por sua vez, são um todo, constituído de hábitos e habilidades que sustentam uma ação.

O mundo do trabalho, cada vez mais, substitui as tarefas puramente físicas por tarefas de produção mais intelectuais. Assim é exigida dos profissionais uma competência que "se apresenta como uma espécie de coquetel individual", que articula a qualificação técnica e profissional à capacidade de trabalhar em equipe, ao comportamento social, à capacidade de iniciativa, dentre outros. O trabalhador competente seria um agente de mudanças em seu ambiente de trabalho (DELORS, 1998, p. 94).

Desenvolver competências, portanto, significa ampliar diferentes atributos (conhecimentos, habilidades e atitudes) que, articulados, proporcionam maneiras de alcançar resultados satisfatórios em alguma atividade (PERRENOUD, 1999). Neste estudo, utilizaremos o termo "competências para educação permanente em saúde" representando a gama de conhecimentos, habilidades e atitudes capazes de sustentar uma prática de efetiva educação permanente no cotidiano das práticas de saúde.

Apesar de encontrarmos o termo "Educação Permanente" como sinônimo de 'Educação Permanente em Saúde' em muitas obras (BRASIL, 2001a; 2001b; 2004a; 2001c; 2007), apresentaremos nos próximos parágrafos um breve 
contexto histórico dos termos, a fim de reforçarmos nossa escolha pelo termo "Educação Permanente em Saúde" (doravante EPS).

Para Gadotti (1992), a Educação Permanente, nascida na área da educação, é uma expressão recente de uma preocupação antiga. Na China, o filósofo LaoTsé, alguns séculos antes de Cristo, dizia que “...todo estudo é interminável” (TAO TO KING, 1967 p. 84 apud GADOTTI, 1992 p. 56).

De acordo com Smaha e Carloto (2010), a produção sobre o tema Educação Permanente foi grande internacionalmente, sendo o francês a principal língua dessas publicações. Dessa maneira, a Educação Permanente passou a ser a ideia principal da Política Educacional da UNESCO, disseminada a partir do projeto "Cidade Educativa", que, almejando implantar educação para a vida toda, foi assumido por vários países, inclusive o Brasil (GADOTTI, 1992).

Após o levantamento nos documentos sobre Educação Permanente em Genebra, Gadotti (1992) conclui que a Educação Permanente tornou-se um discurso de ideologias diferentes do que vinha sendo disseminado pela UNESCO. Segundo o autor, a Educação Permanente para os trabalhadores serve para que eles se tornem mais rentáveis e adaptáveis às mudanças econômicas e industriais. No entanto, a Política de Saúde trouxe a proposta da Educação Permanente para a área tendo em vista a premissa de atender as necessidades sociais que emergem conforme as constantes mudanças mundiais, preparando o indivíduo em suas potencialidades e buscando melhorar a qualidade do atendimento do serviço (BÁRCIA, 1982).

A Organização Pan-Americana de Saúde (OPAS), tendo conhecimento das falhas na formação das equipes de saúde, sugeriu, na década de 1970, um debate para a construção de um novo modelo pedagógico que melhorasse as práticas na saúde (LOPES et al., 2007). Iniciou-se então, um processo de busca nos documentos da UNESCO sobre as bases da Educação Permanente, até aquele momento debatida exclusivamente na área da educação (SMAHA; CARLOTO, 2010).

A temática ganha maior destaque em cenário nacional em 2004, por meio da Portaria no 198, que instituiu a Política Nacional de Educação Permanente em Saúde (PNEPS), reformulada posteriormente em 2007. A política propunha transformar as práticas de formação, atenção, gestão e controle social, tendo como grande desafio romper com a lógica da repetição e da fragmentação dos cursos de capacitação (BRASIL, 2007). 
A educação permanente se baseia na aprendizagem significativa e na possibilidade de transformar as práticas profissionais. A educação permanente pode ser entendida como aprendizagem-trabalho, ou seja, ela acontece no cotidiano das pessoas e das organizaçôes. Ela é feita a partir dos problemas enfrentados na realidade e leva em consideração os conhecimentos e as experiências que as pessoas já têm (BRASIL, 2007, p. 20).

Entendemos hoje, dez anos após a publicação da primeira versão da PNEPS, que as discussões atuais sobre a EPS e a educação superior caminham de forma atrelada, na medida em que ambas se apoiam no conceito de ensino problematizador e em métodos de ensino baseados na aprendizagem significativa. Estes defendem um processo de ensino-aprendizagem inserido de maneira crítica na realidade, que se interesse pelas experiências anteriores pessoais do aluno, e desconsidere a superioridade do educador em relação ao educando (BERBEL, 1998).

Observamos a interface EPS e Educação Superior também na Lei de Diretrizes e Bases para a Educação Nacional. Para esta, a educação superior tem por finalidade, entre outros:

[...] V-suscitar o desejo permanente de aperfeiçoamento cultural e profissional e possibilitar a correspondente concretização, integrando os conhecimentos que vão sendo adquiridos numa estrutura intelectual sistematizadora do conhecimento de cada geração;

VI - estimular o conhecimento dos problemas do mundo presente, em particular os nacionais e regionais, prestar serviços especializados à comunidade e estabelecer com esta uma relação de reciprocidade;

VII - promover a extensão, aberta à participação da população, visando à difusão das conquistas e benefícios resultantes da criação cultural e da pesquisa científica e tecnológica geradas na instituição (BRASIL, 1996, p. 16).

Acreditamos que as diretrizes curriculares nacionais utilizaram o termo "Educação Permanente" se referindo à aplicação deste à área da saúde, ou seja, compreendendo-o como "Educação Permanente em Saúde". Cabe ressaltarmos que a elaboração das diretrizes se deu antes da definição do termo "Educação Permanente em Saúde” pela PNEPS de 2004 (BRASIL, 2004b).

$[\mathrm{O}] \mathrm{s}$ profissionais devem ser capazes de aprender continuamente, tanto na sua formação, quanto na sua prática. Dessa forma, os profissionais de saúde devem aprender a aprender e ter responsabilidade e compromisso com a educação e o treinamento/ estágios das futuras gerações de profissionais, não apenas transmitindo conhecimentos, mas proporcionando condições para que haja beneficio mútuo entre os futuros profissionais e os profissionais dos serviços (BRASIL, 2001a; 2001b; 2001c; 2004a). 
Tendo em vista que a EPS consta de documentos oficiais que regem a educação superior nacional, decidimos buscar na literatura trabalhos que tivessem como objeto a competência para EPS no ensino de graduação.

O perfil de publicaçôes encontrado constituiu-se de artigos que tiveram por objetivo observar a abordagem de algum tema na formação, e que tenham citado a EPS como uma maneira de sensibilizar os profissionais já graduados sobre o tema. Outros artigos trouxeram como objetivo analisar relações entre alunos e o campo de prática, citando assim a EPS como benefício trazido pelos alunos ao campo. Outros ainda referiram que cursos de extensão, residência e pósgraduação seriam estratégias de EPS (BUSSANELLO et al., 2011; LIMA et al., 2009; ROSA; LOPES, 2010).

Encontramos apenas um trabalho que versa sobre a temática (OLIVEIRA et al., 2013). Porém, este trata do ensino de graduação em Enfermagem e está disponível apenas em resumo expandido em anais de um congresso de Enfermagem. Portanto, existe uma lacuna de estudos que articulem a EPS e o ensino de graduação. Assim, propomo-nos a aprofundar nossos conhecimentos sobre a percepção de coordenadores de graduações da saúde sobre a competência para EPS.

Consideramos que a EPS se relaciona diretamente com a qualidade da assistência, a autonomia profissional, a integralidade e a ética social, e que é responsabilidade das instituiçôes de ensino, inclusive preconizada pelas diretrizes curriculares nacionais, a formação de profissionais competentes para se educarem permanentemente em saúde. Portanto, apresentamos a seguinte pergunta de pesquisa: como coordenadores de cursos de graduação da área da saúde percebem a competência para a EPS?

Acreditamos que os coordenadores pedagógicos são, além de docentes, representantes dos cursos, uma vez que assumem papel fundamental nas articulações institucionais. Assim, este trabalho pretende trazer uma análise das relações existentes entre o que se prevê nos Projetos Político-Pedagógicos (PPP) e a visão dos coordenadores sobre a competência para a EPS durante a graduação.

Este trabalho teve como objetivo compreender a percepção de coordenadores de cursos de graduação sobre Educação Permanente em Saúde e identificar sua visão sobre quais habilidades, conhecimentos e atitudes compõem a competência para EPS. 
O estudo foi do tipo descritivo e exploratório, de abordagem qualitativa, escolhida devido a nosso objeto constituir-se no campo da subjetividade. O local da pesquisa foi a Universidade Federal de Mato Grosso (UFMT), nas sedes dos cursos de Medicina, Enfermagem, Nutrição e Psicologia, campus de Cuiabá. Tiveram representação neste estudo os cursos de graduação relacionados à área da saúde, oferecidos pela universidade, que previam a Educação Permanente em Saúde preconizada pelas Diretrizes Curriculares Nacionais do curso (DCNs).

Todos os cursos pesquisados são de caráter integral, sendo que as graduações em Nutrição, Enfermagem e Medicina desenvolvem suas atividades nos períodos matutino e vespertino, e a graduação em Psicologia, nos períodos vespertino e noturno.

Os dados desta pesquisa foram provenientes de duas técnicas de coleta de dados: análise documental dos projetos político-pedagógicos e entrevistas semiestruturadas com os coordenadores dos cursos.

Para a análise documental, utilizamos um instrumento previamente elaborado, que previa quatro eixos, nomeados, após a análise, "núcleos de sentido": 1) Dados gerais; 2) Bases teóricas da educação permanente; 3) Estratégias pedagógicas; e 4) Competências previstas que dialogam com a EPS. Dessa forma, em papel de painel, escrevemos os núcleos e, lendo os planos, identificamos frases, parágrafos, tabelas, gráficos e até páginas que constituiriam tais núcleos. Cabe ressaltar que deixamos espaço em branco para algum núcleo de sentido que por ventura emergisse de maneira empírica, sem previsão no instrumento.

Assim, recortávamos os trechos dos PPPs e colávamos no espaço destinado à unidade de busca que representavam. Após esse processo, obtivemos como resultado um grande "tapete" - o chamamos assim por nos remeter à tessitura das partes junto ao todo, em um processo manual de bricolagem. Esse grande "tapete", resultante da análise dos documentos, nos permitiu a visualização de todo o conteúdo dos projetos.

Avaliamos a importância de construirmos o instrumento a partir do referencial teórico, pois este nos proporcionou uma visão ampla do desenvolvimento da competência para a EPS. Sendo assim, já na análise documental, pudemos 
perceber algumas características particulares de nosso objeto de estudo, as quais seriam confirmadas após a análise das entrevistas.

Após esboçarmos o "tapete", partimos para a análise das falas dos coordenadores. As entrevistas foram transcritas na íntegra e, após recorrentes leituras, decidimos por abordar os assuntos discutidos pelos participantes baseando-nos nos eixos do roteiro previamente elaborado utilizado durante as entrevistas.

Analisamos as falas por meio do roteiro, do qual constavam 5 eixos, que se transformaram, após análise, em núcleos de sentido: 1) Perfil do entrevistado; 2) Percepção sobre a interface ensino/trabalho; 3) Percepção sobre EPS; 4) A Educação Permanente e o ensino de graduação; e 5) Competência para EPS. $\mathrm{O}$ mesmo processo de tessitura foi realizado para essa análise, resultando em outro "tapete" com núcleos de sentido nutridos pelos dados provenientes das entrevistas. Além de nutrir os núcleos previstos no instrumento, os dados também ocuparam o espaço em branco que havíamos reservado, resultando em um núcleo de sentido emergido empiricamente.

Devido à complexidade do assunto, notamos que muitas informações contidas nas entrevistas nutriam não apenas um, mas diferentes núcleos de sentido dos resultados. Sendo assim, tomamos o cuidado de reavaliar cada núcleo, buscando elementos que poderiam ser adicionados por todo o conteúdo da descrição, e não somente na unidade de busca do roteiro a que pertenciam.

Este trabalho foi submetido ao Comitê de Ética em Pesquisa do Hospital Universitário Júlio Muller e aprovado no dia 09 de abril de 2014 sob o parecer de número 610.301, atendendo à resolução 466/2013. Foi solicitado o consentimento dos participantes para realizar a entrevista pedindo que assinassem o Termo de Consentimento Livre e Esclarecido (TCLE). Foi garantido o anonimato de suas identidades e o uso das informações fornecidas somente em trabalho científico.

\section{Resultados e discussão}

Tendo em vista que, para compreender a percepção dos coordenadores dos cursos de graduação da saúde sobre a competência para EPS, fez-se necessário, primeiramente, compreender sua percepção sobre a EPS, de maneira geral, abordamos nossos resultados em dois momentos, a saber: 1) Concepções acerca da EPS, e 2) A composição da competência para EPS. 


\section{Concepções acerca da EPS}

Os PPP analisados abordam a EPS com diferentes enfoques. Alguns projetos não a citam em nenhum momento de suas construções, apenas trazem como princípios o aprimoramento e a capacitação contínuos. Sendo assim, não apresentam a concepção de EPS nem fazem uso do termo. Outros apresentaram como concepção de EPS o processo ininterrupto de aprendizagem, associando-a à autoaprendizagem, o que faria parte do perfil almejado do profissional.

Há PPPs que citam a EPS no momento em que discorrem sobre as competências. Nestes, ela é apresentada tal como nas Diretrizes Curriculares Nacionais, ipsis litteris.

Também observamos a PNEPS sendo apresentada como justificativa dos planos. Porém, apesar de citarem a EPS em sua justificativa, não deixam claras suas concepções ao tratarem do termo 'Educação Permanente em Saúde’.

[...] o processo ininterrupto de aprendizagem [...], que a graduação não esgota, devendo, ao contrário, favorecer com flexibilidade de raciocínio e capacidade de adaptação (PPP-3).

Em processo de articulação com o Ministério da Educação, o Ministério da Saúde (MS) vem investindo na produção específica de mudanças na formação e no desenvolvimento dos trabalhadores da saúde, o que se consubstanciou na Política de Educação Permanente em Saúde (PEP) de 2004 (PPP-4).

Os coordenadores, de maneira geral, relatam não ter domínio sobre o tema. Por muitas vezes, questionaram o entrevistador e/ou afirmaram não saber versar ao certo sobre o tema:

$\mathrm{Ai}$, eu acho que eu misturo tudo! (Coo-1).

É isso mesmo? Ou não? (Coo-4).

Esse termo não é muito falado, né?! (Coo-3).

As concepções relatadas pelos entrevistados foram direcionadas prioritariamente à dimensão pessoal da EPS, limitando-se ao aprendizado durante e após a graduação, de maneira independente, e à potência dessa ação de transformar a realidade do trabalho.

É você conseguir ao longo de sua caminhada, na graduação, na pós, e no exercício profissional, aprender a todo momento né? Eu me confundo, não sei [...] é a capacidade de você mobilizar o que você já sabe com o contexto que está inserido (Coo-1).

[...] é uma transformação continua do trabalho, é isso? [...] a educação permanente tem que ser transformadora da realidade do nosso trabalho, né? (Coo-4). 
[...] é ir atrás de boas fontes, é ter curiosidade, é o profissional se interessar por pesquisa, auxiliar o colega que ainda está em formação (Coo-2).

[...] é o processo de aprendizado ao longo de toda a formação (Coo-3).

A EPS, para os participantes, se diferencia da Educação Continuada. Esta requer cursos com metodologias tradicionais, ao passo que aquela teria como foco a autonomia/independência, e os momentos de aprendizagem seriam em equipe, utilizando metodologias inovadoras. Porém, notamos que a EPS, para os coordenadores, tem o objetivo de atualização e aperfeiçoamento técnico do profissional, a fim de torná-lo mais competitivo para o mercado de trabalho.

Isso eles aprendem sim, desde o início. Mesmo eu que estou formado(a) há [...] anos, se eu parar, se eu não fizer algum curso, alguma coisa, você fica parado no tempo $(\mathrm{Coo}-3)$.

[...] enquanto na graduação você tem 4, 5 anos ou até 6 anos né? [...] de uma chuva de informação [...], mas são 6 anos no máximo, o resto você vai ter aí, 20, 30 anos de informação para você se manter atualizado, pra você se garantir né? (Coo-1).

Sobre a EPS nos PPP, notamos que estes não apresentam uma concepção específica. Identificamos desde projetos que não citavam o termo, nem contemplavam a EPS em sua descrição de competências, até aqueles que citavam o termo, a política e contemplavam-na parcialmente em sua descrição de competências. Porém, nenhum dos projetos relatou sua concepção sobre EPS.

Posicionamo-nos a favor da necessidade dos projetos descreverem a concepção de seus autores sobre EPS e se aprofundarem na abordagem desta no momento da definição de competências, superando a descrição proposta pelas diretrizes, pois a entendemos como reduzida, uma vez que não contempla a complexidade do tema.

Sabemos que a concepção de EPS vai além do "aprender a aprender" e da responsabilidade por gerações futuras de profissionais. A EPS, para nós, é entendida, ao mesmo tempo, como uma "prática de ensino-aprendizagem" e como "uma política de educação na saúde' (CECCIM; FERLA, 2009, p. 1).

Segundo Ceccim e Ferla (2009), a EPS como "prática de ensino-aprendizagem” está relacionada à produção de conhecimentos no cotidiano das instituições de saúde, a partir da realidade vivida pelos sujeitos envolvidos, tendo como base de interrogações os problemas enfrentados no dia a dia do trabalho e as experiências desses sujeitos. Como "política de educação na saúde", a EPS representa a contribuição do ensino à construção do Sistema Único de Saúde (SUS), na medida em que tanto as políticas de saúde como as diretrizes curriculares nacionais para 
a formação dos profissionais da área buscam inovar na proposição de articulações entre o ensino, o trabalho e a cidadania.

Sobre a utilização nos projetos político-pedagógicos da mesma descrição trazida pelas Diretrizes Curriculares Nacionais ao dissertar sobre a competência para EPS, acreditamos ser uma tentativa do corpo docente de adaptar o projeto às diretrizes, de caráter obrigatório para o funcionamento dos cursos. Porém, a literatura atual (CECCIM; FEUERWERKER, 2004; CECCIM; FERLA, 2009; CECCIM, 2005) apresenta subsídios para aprofundamento do tema, e nos questionamos, portanto, se o corpo docente tem discutido os elementos das diretrizes a fim de colocar em prática não apenas o que é preconizado de maneira mandatória, mas também as convicções dos sujeitos envolvidos no processo de construção do PPP.

A universidade também precisa repensar se tem feito uso de sua autonomia. A Lei 55/40, de 1968, prevê que "[a]s universidades gozarão de autonomia didáticocientífica, disciplinar e financeira, que será exercida na forma da lei e dos seus estatutos" (BRASIL, 1968, p. 1). Foi exercendo essa autonomia que, na década de 1980, em plena ditadura militar, produções científicas denunciavam o autoritarismo nas práticas de saúde e defendiam a democratização da saúde (PAIM, 2009).

Paim (2009) afirma que a proposta da reforma sanitária foi resultado da articulação entre as lutas sociais e a produção do conhecimento (grifo nosso) e que para o enfrentamento da crise da saúde foram necessárias uma prática teórica, produtora de conhecimentos, e uma prática política, voltada à mudança das relações sociais (AROUCA, 1975).

Assim, consideramos que a universidade pode interferir ativamente na elaboração de políticas e precisa repensar conteúdos de decretos e portarias governamentais em prol de continuamente questioná-los e/ou melhorá-los. Faz-se necessária a reintrodução do conhecimento pertinente na elaboração dos projetos.

Para Morin, Ciurana e Motta (2004, p. 38), “[é] necessário reintroduzir o papel do sujeito / observador / pensador / elaborador / estrategista em todo o conhecimento", ou seja, o sujeito se entender como reconstrutor da realidade. Assim, os sujeitos elaboradores dos projetos precisam refletir sobre a EPS, buscando aprofundamento do tema de maneira autônoma, a fim de que a formação do futuro profissional seja permeada pela EPS, que comporta significados para além dos previstos por instâncias superiores. 
Não limitada apenas aos PPPs, a falta de compreensão da complexidade da EPS alcança os próprios coordenadores dos cursos, que, por sua vez, reconhecem sua falta de domínio sobre o tema.

Para Cortez (2013), existe dificuldade em se conceituar de forma clara os termos "Educação Permanente em Saúde" e "Educação Continuada" devido à própria literatura apresentar de maneira diferente e com diversas nomenclaturas os processos de educação para o trabalho. Porém, chama-nos a atenção o desconhecimento do termo e da política, apesar de implantados há mais de dez anos em âmbito nacional. $\mathrm{O}$ desconhecimento do termo pelos coordenadores e a não abordagem da EPS pelos planos revelam sua falta de representatividade no ambiente acadêmico.

Apesar de afirmarem que têm dificuldade para compreender o termo, os participantes relataram suas concepções sobre ele. Foi possível identificarmos uma concepção limitada de EPS pelos participantes, pois, apesar de citarem as metodologias ativas e a transformação da realidade, ainda concebem a EPS nos moldes da Educação Continuada, ou seja, visando o aperfeiçoamento pessoal como necessário à competitividade no mercado de trabalho, na qual a transformação da realidade é caracterizada pela não acomodação/passividade frente às inovações.

Defendemos que, além do aperfeiçoamento, a EPS possui potencial político, no qual precisam ser concebidos o quadrilátero da formação, a construção da cidadania e o aprender na, pela e para a prática. Essas concepções não foram encontradas nas falas dos participantes.

Acreditamos que a compreensão dos participantes sobre EPS tecem-se por relação sistêmica, uma vez que as concepções sobre o termo são maiores do que a soma dos princípios, ou seja, o termo remete à vivência, a tentativas exitosas ou malsucedidas que podem ir além dos princípios e são, ao mesmo tempo, menores, devido a equívocos e/ou o desconhecimento do termo e de seus princípios.

\section{A composição da competência para EPS}

Entendemos a competência para a EPS como uma combinação individual composta de conhecimentos habilidades e atitudes que sustentam uma ação. Assim, os entrevistados foram questionados sobre o que forma a competência necessária a um profissional para que este efetive a EPS em seu cotidiano de trabalho. 
Sabemos que os elementos da competência são indissociáveis. Porém, para fins didáticos, os separamos em "conhecimentos", relacionados ao saber conhecer, "habilidades", relacionadas ao saber fazer, e "atitudes", relacionadas ao saber ser (DELORS, 1998).

Para nossos entrevistados, a competência para Educação Permanente é composta conforme a figura 1 , a seguir:

Figura 1: A competência para EPS na percepção de coordenadores de cursos de graduação da saúde, 2014.

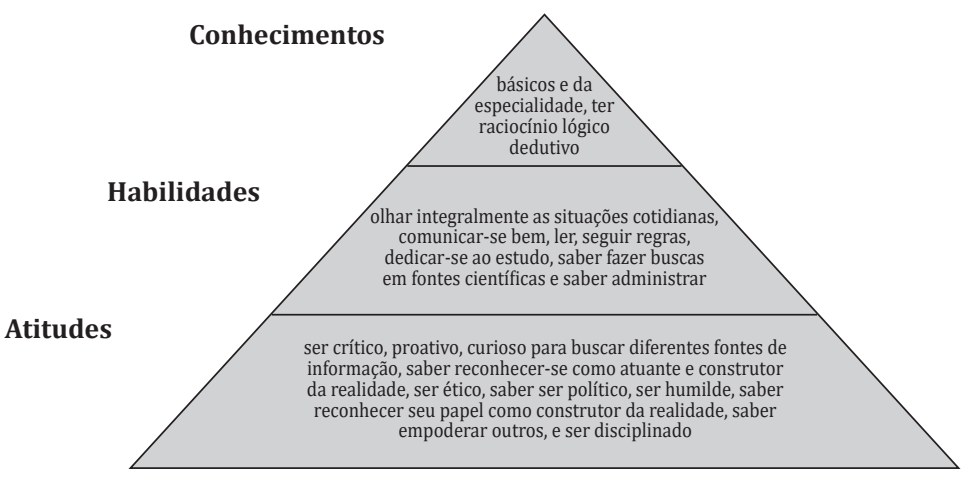

Fonte: Elaboração própria.

Na pirâmide, nota-se que os coordenadores priorizam a dimensão atitudinal, concebendo-a como a base da competência. Relataram que, na dimensão do saber conhecer, o aluno precisa se apropriar de conhecimentos básicos de sua formação e de sua especialidade e ter raciocínio lógico dedutivo.

Ter conhecimento, além do básico, e aí depois na especialidade (Coo-3).

É ter capacidade de raciocínio lógico e dedutivo (Coo-1).

$\mathrm{Na}$ dimensão das habilidades, o aluno necessita olhar integralmente as situações cotidianas, comunicar-se bem, ler, seguir regras, dedicar-se ao estudo, saber fazer buscas em fontes científicas e saber gerenciar.

[...] eu te diria que, muito básico, é saber ler e seguir regras é [...] isso para mim é [...] parece tão bobo mas pra mim isso já é uma boa parte: alguém que saiba compreender regras simples (Coo-2).

[...] é ter habilidade administrativa (Coo-4).

eu acho que habilidade do diálogo [...] dialogando com outras disciplinas [...] não dá para caminhar sozinho (Coo-3). 
Por fim, na dimensão atitudinal, o aluno precisa ser crítico, proativo e curioso para buscar diferentes fontes de informação, saber reconhecer-se como atuante e construtor da realidade, ser ético, político, humilde e disciplinado.

[...] desenvolver postura ética (Coo-4).

tem que deixar de ser um reprodutor do sistema [...] tem que se reconhecer como sujeito[...] Eu acho que ele tem que ter o técnico mas ele tem que situar no contexto macro [...] que seja capaz de lutar pelos seus direitos e deveres (Coo-1).

Foi observado que os participantes demonstraram dificuldades em relatar tanto suas concepções sobre EPS quanto as dimensões da competência para EPS. Sobre isso, é importante ressaltarmos que o conhecimento dos participantes sobre o que constitui a competência para EPS depende de sua perspectiva sobre o termo. As respostas dos entrevistados sobre a constituição da competência para EPS demonstram que estes priorizam a dimensão atitudinal em detrimento das demais (cognitiva e técnica), concebendo-a como a base da competência.

No entanto, até à década de 90, acreditava-se que o homem funcionava melhor sem a interferência de emoções (ESQUÍVEL, 2011). Somente nas últimas décadas é que houve um crescente interesse da comunidade científica pelo estudo do conceito de competência emocional, que estaria relacionado à teoria de que pessoas com maior inteligência emocional seriam mais bem sucedidas no mercado de trabalho (LIMA SANTOS; FARIA, 2005)

Para Farinha e Tomasi (2011), o trabalho passou a não prescindir da capacidade inventiva e participativa do trabalhador. Sendo assim, os processos de recrutamento e seleção passaram a valorizar mais as atitudes e comportamentos dos trabalhadores do que saberes escolarizados e tempo de experiência na função.

Ademais, alguns estudos (FARIA; COSTA; COSTA, 2008; FARIA; LIMA SANTOS, 2006; LIMA SANTOS; FARIA, 2005) assumem que o desenvolvimento do aspecto atitudinal promove comportamentos mais eficazes e estimula a melhoria da competência como um todo. Assim, parece-nos que a concepção de nossos entrevistados, aliada a essas discussões, ajuda a fomentar a articulação entre teoria e empirismo, contrapondo a máxima da oposição entre o mundo cognitivo e o mundo emocional.

Porém, apesar de discutirem sobre a composição da competência para EPS, existem coordenadores que relatam que as graduações que coordenam não a desenvolvem. Concebemos a falta de desenvolvimento da competência para EPS como uma realidade complexa e, portanto, multicausal. Contudo, percebemos 
a concepção de EPS equivocada dos coordenadores como uma dessas causas, sendo que esta, por sua vez, estabelece relação recursiva ao ser vinculada à falta de desenvolvimento da competência para EPS na graduação. Essa relação é ilustrada a seguir, por meio da figura 2 .

Figura 2: A relação recursiva entre a concepção de coordenadores e o desenvolvimento da competência para EPS nos cursos de graduação da área da saúde, 2014.

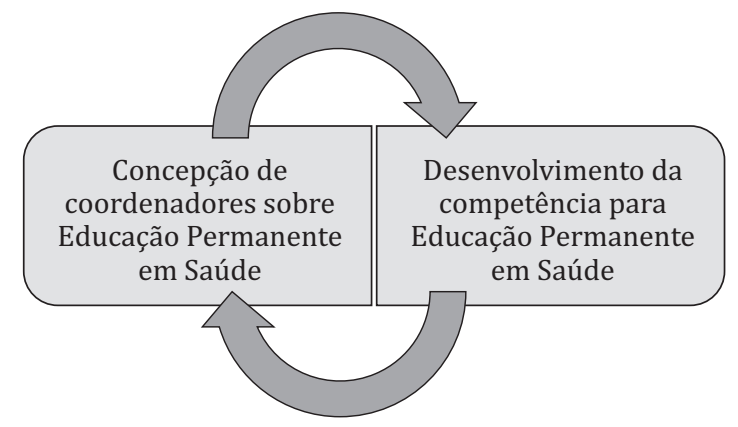

Fonte: Elaboração própria.

Para Morin, Ciurana e Motta (2004, p. 36) "é recursivo um processo cujos produtos são necessários para a produção do próprio processo”. Esse seria o princípio fundamental para entender os fenômenos de autoprodução e auto-organização. Assim, entendemos que os coordenadores são produto de uma formação que não estimulou o conhecimento sobre a EPS, e também são produtores, pois devido ao próprio desconhecimento perpetuam a falta de abordagem sobre o assunto na graduação, apesar de afirmarem que é necessário que ela contemple a EPS.

O corpo docente precisa compreender a EPS a fim de que o PPP seja construído transversalmente por esta, constando seus princípios em todos os momentos do curso, bem como priorizar a integração entre ensino-serviço-comunidade.

\section{Considerações finais}

Chama-nos a atenção a falta de conhecimento dos coordenadores sobre a EPS, uma vez que a Política Nacional foi lançada ainda em 2004, completando, em 2014, dez anos de implementação. Ademais, as Diretrizes Curriculares Nacionais preconizam a Educação Permanente como competência básica do egresso, fato que deve estimular o corpo docente na busca por mais conhecimento sobre o tema. 
De igual forma, os PPPs precisam conter as concepções do corpo docente sobre EPS, assim como abordá-la no momento da definição de competências, superando a descrição proposta pelas DCNs. Compreendemos a descrição de competência para EPS trazida pelas DCNs como parcial, uma vez que não contempla a complexidade do tema. Sendo assim, questionamo-nos se o corpo docente tem discutido os elementos das diretrizes a fim de colocar em prática não apenas o que é preconizado de maneira mandatória, mas também as convicções dos sujeitos envolvidos no processo de construção do PPP.

Entendemos que os coordenadores são produto de uma formação que não estimulou o conhecimento sobre a EPS e também são produtores, pois devido ao próprio desconhecimento perpetuam a falta de abordagem sobre o assunto na graduação, apesar de afirmarem que é necessário que a graduação contemple a EPS.

Assim, reafirmamos à universidade sua força política para repensar conteúdos de decretos e portarias governamentais em prol de continuamente questionálos e/ou melhorá-los. Contudo, observamos que as dificuldades relatadas por nossos participantes para o desenvolvimento da competência para EPS foram mais significativas e numerosas do que as facilidades, remetendo-nos à urgente necessidade de rearticularmos cursos de graduação, faculdades e setores dentro da instituição de ensino, a fim de que reorganizem processos internos e exerçam essa força política com o propósito de transformar processos externos.

Tendo em vista que as bases teóricas da EPS - a saber, a autonomia, a cidadania, a subjetividade dos atores e o aprender na/pela/para a prática - estabelecem relação direta com a inovação de métodos de ensino/aprendizagem proposta e discutida por tantos autores na área da educação, entendemos que os desafios para a incorporação dos princípios da EPS são os mesmos encontrados para a mudança de processos tradicionais, fragmentados e "bancários" de ensino para processos inovadores, que interligam saberes e que visam a reinserção dos objetos de estudo ao seu contexto macro. ${ }^{1}$

\section{Referências}

AROUCA, A. S. Introdução à crítica do setor saúde. Nêmesis, n. 1, p. 17-24, 1975.

BÁRCIA, M. F. Educação Permanente no Brasil. Petrópolis: Vozes, 1982.

BRASIL. Lei no 9.394, de 20 de dezembro de 1996. Estabelece as diretrizes e bases da educação nacional. Diário Oficial [da República Federativa do Brasil], Brasília, DF, v. 134, n. 248, 23 dez. 1996. Seção I, p. 27834-27841. 
CE no4 de 7 de novembro de 2001a: Institui diretrizes curriculares nacionais do curso de graduação em Medicina. Diário Oficial da União, Brasília, DF.

. Conselho Nacional de Educação. Câmara de Educação Superior. Resolução CNE/ CE no 05 de 07 de novembro de 2001b: Institui diretrizes curriculares nacionais do curso de graduação em Nutrição. Diário Oficial da Uniāo, Brasília, DF.

. Conselho Nacional de Educação. Câmara de Educação Superior. Resolução CNE/ CES no 3, de 7 de novembro de 2001c. Institui Diretrizes Curriculares Nacionais do Curso de Graduação em Enfermagem. Diário Oficial da União, Brasília, DF.

. Conselho Nacional de Educação. Câmara de Educação Superior. Resolução CNE/

CES no 8, de 7 de maio de 2004a. Institui Diretrizes Curriculares Nacionais do Curso de Graduação em Psicologia. Diário Oficial da União, Brasília, DF.

. Ministério da Saúde. Portaria GM/MS no 1.996, de 20 de agosto de 2007, Dispóe sobre as diretrizes para a implementação da Política Nacional de Educação Permanente em Saúde e dá outras providências. Brasília, 2007.

. Ministério da Saúde. Portaria no 198, de 13 fevereiro de 2004. Institui a Política Nacional de Educação Permanente em Saúde. Diário Oficial da União, Brasília, DF, n.32, 2004b.

. Lei n. 5540 de 28/11/ 1968. Fixa normas de organização e funcionamento do ensino superior e sua articulação com a escola média, e dá outras providências. Diário Oficial União de 29/11/ 1968, retificado no D.O. de 3/12/ 1968

BERBEL, N. A. N. A problematização e a aprendizagem baseada em problemas. Interface - Comum. Saúde e Educ., v. 2, n. 2, p. 139-154, 1998. Disponível em: <http://www.scielo. br/pdf/icse/v2n2/08>. Acesso em: 18/04/15.

BUSSANELLO, J et al. Humanização do parto e a formação dos profissionais da saúde. 2011. Disponível em: <http://periodicos.uem.br/ojs/index.php/CiencCuidSaude/article/ view/8533>. Acesso em: 22/10/14.

CECCIM, R. B. Educação Permanente em Saúde: descentralização e disseminação de capacidade pedagógica na saúde. Ciênc. saúde coletiva, v. 10, n. 4, p. 975-986, 2005

CECCIM, R. B.; FERLA, A. A. Educação permanente em saúde. Dicionário da Educação Profissional em Saúde. Fundação Oswaldo Cruz. Escola Politécnica de Saúde Joaquim Venâncio. 2009. Disponível em: <http://www.epsjv.fiocruz.br/dicionario/verbetes/ edupersau.html>. Acesso em: 25/11/2013

CECCIM, R. B.; FEUERWERKER, L. C. M. Mudança na graduação das profissões. Cad. saúde pública, v. 20, n. 5, p. 1400-1410, 2004. 
CORTEZ, E. A. Educação permanente, continuada e em serviço: desvendando seus conceitos. Enfermería Global, n. 29, p. 324, 2013.

DELORS, J. (Org.). Educação: um tesouro a descobrir. 8a ed. São Paulo: Cortez; Relatório para a UNESCO da Comissão Internacional sobre Educação para o Século XXI. 1998.

ESQUIVEL, L. O livro das emoções. $5^{\mathrm{a}}$ ed. Alfragide: Edições Asa. 2011.

FARIA, L.; COSTA, A.; COSTA, M. Validação do Questionário de Competência Emocional (QCE): Estudo em contexto hospitalar com enfermeiros. Actas da XIII Conferência Avaliação Psicológica: Formas e Contextos. Braga: Psiquilíbrios, 2008. p. 923-930.

FARIA, L.; LIMA SANTOS, N. Competência emocional: Adaptação e validação intercultural do Emotional Skills and Competence Questionnaire (ESCQ). Actas da XI Conferência Internacional de Avaliação Psicológica: Formas e Contextos. Braga: Psiquilíbrios, 2006. p. 349-356.

FARINHA, C. A.; TOMASI, A. P. N. A competência no recrutamento e seleção de trabalhadores: Um processo de construção de identidade, de cultura e de educação. 2011. Disponível em: <http://www.umcpos.com.br/centraldoaluno/arquivos/18_10_2011_138/ Estudo_caso_Selecao_por_comp_18.10.pdf>. Acesso em: 22 de outubro de 2014

GADOTTI, M. A educação contra a educação: o esquecimento da educação e a educação Permanente. 5a ed. Rio de Janeiro: Paz e Terra, 1992.

LIMA SANTOS, N.; FARIA, L. Inteligência emocional: Adaptação do "Emotional Skills and Competence Questionnaire" (ESCQ) ao contexto português. Revista da Faculdade de Ciências Humanas e Sociais da UFP, v. 2, p. 275-289, 2005.

LIMA, S. G et al. Educação permanente em SBV e SAVC: impacto no conhecimento dos profissionais de enfermagem. Arquivos Brasileiros de Cardiologia, v. 93, n. 6, p. 630-636, 2009.

LOPES, S. R. S. et al. Potencialidades da educação permanente para a transformação das práticas de saúde. Comun. ciênc. saúde, v. 18, n. 2, p. 147-155, 2007.

MORIN, E; CIURANA, E. R.; MOTTA, R. D. Educar na era planetária-o pensamento complexo como método de aprendizagem no erro e na incerteza humana. São Paulo: Cortez, 2004.

OlIVEIRA, J. M. et al.. Práticas de Educação Permanente em Saúde na Formação dos Enfermeiros. In: SEMINÁRIO NACIONAL DE PESQUISA EM ENFERMAGEM. 17. Anais... v. 1, n. 1, Natal, RN: ABEn, 2013. ISSN: 2237-3454. Disponível em: <http://www. abeneventos.com.br/anais_senpe/17senpe/index.htm>. Acesso em: 15/10/14

PAIM, J. S. Uma análise sobre o processo da Reforma Sanitária brasileira. Saúde em Debate, v. 33, n. 81 , p. $27-37,2009$.

PERRENOUD, P. Construir as competências desde a escola. Porto Alegre: Artmed, 1999. 
ROSA, S. D.; LOPES, R. E. Residência multiprofissional em saúde e pós-graduação lato sensu no Brasil: apontamentos históricos. Trab. educ. saúde, v. 7, n. 3, p. 479-498, 2010.

SMAHA, I. N.; CARLOTO, C. M. Educação permanente: da pedagogia para a saúde. VII Seminário do Trabalho: trabalho, educação e sociabilidade, p. 24-28, 2010.

\section{Nota}

${ }^{1}$ L. P. S Lima concebeu o projeto, realizou a análise e interpretação dos dados e redigiu o artigo. M. R. R Ribeiro participou da concepção do projeto e da análise dos dados. 
The competence for Permanent Education in Health: perceptions of coordinators of health undergraduate courses

Descriptive, exploratory qualitative study. It aimed to understand the perception of coordinators of health courses - Nutrition, Nursing, Medicine and Psychology - about Permanent Education in Health and identify which skills, knowledge and attitudes make up this competence. We discuss our results in two stages, namely: 1) conceptions about the Permanent Education in Health, and 2) The composition of the Permanent Education in Health. We understand that the challenges for the incorporation of the principles of Permanent Education in Health are the same found for the disruption of the traditional teaching / learning processes.

Key words: education, continuing education; permanent education in health. 